\title{
Analysis of 6-10-Year-Old Children Feet Anthropometric Sizes and Pes Planus, Pes Cavus Predisposition in Central Anatolia
}

\section{Serap Alsancak}

Ankara University

Senem Güner ( $\nabla$ sguner@ankara.edu.tr )

Ankara University

Enver Guven

Ankara University

Ali Özgün

Ankara University

Yunis Akkaş

Ankara University

Neslihan Alkış

Ankara University

\section{Research Article}

Keywords: Children, Foot anthropometric, Pes Planus, Pes Cavus

Posted Date: January 25th, 2021

DOl: https://doi.org/10.21203/rs.3.rs-148910/v1

License: (1) This work is licensed under a Creative Commons Attribution 4.0 International License.

Read Full License 


\section{Abstract}

Background: Information on the foot structures of Central Anatolian children is limited. Foot structures of children aged 6-10 years were shown to be different according to sex and increasing age.

Objective: This study aimed to compare the foot anthropometric values by age and sex and collect the foot anthropometric data to reveal the relationship between pes planus and pes cavus in the arches of children according to age.

Methods: Footprints of 335 children (180 boys and 155 girls) aged 6-10 years were taken by the footprint method and evaluated using 18 different parameters. To examine the relationship between the parameters, normality values were examined. Independent samples t-test was used to analyze sex differences in terms of foot size and shape.

Results: Correlations between other parameters were determined using the correlations analysis method. TFL (Truncated foot length), metatarsal circumference, and foot length were strongly correlated with age in the children. Foot rotation increased with body mass index in the girls compared to that in the boys.

Conclusions: Planning shoe production accordingly will contribute to the development of healthy feet in children. This article focused on foot structures of in Central Anatolia and to identify early foot deformities in children. This study found that the length of the TFL was smaller in boys than in girls.

\section{Introduction}

When designing shoes for any age group, anthropometric data of that group is of great importance. The use of correct foot sizes improves one's foot health and comfort. Shoes that do not fit the foot structure used at a young age can lead to permanent foot deformities. However, foot deformities that can be noticed at a young age can be eliminated before reaching the developmental period. Foot measurements can be taken by different methods. These are measuring with a caliper or tape measure, threedimensional scanning, photographing, or foot-printing [1].

When studies on a similar subject are examined, foot morphologies may vary between sexes and different populations. As a result, the data obtained in this study vary according to age and sex [2-4]. Using these data, designing shoes, which is unique to foot morphology, can be beneficial for children's foot health.

Previous studies have determined the morphological dimensions of feet according to age groups in different nations. In Turkey, there are studies from anthropological studies such as sex prediction made from adult foot structure when examined. In this study, we aimed to determine the foot dimensions of the 6 - 10-year-old children in Central Anatolia and to identify early foot deformities in children.

\section{Materials And Methods}


This study included a sample group of 335 children (155 girls, 180 boys) aged between 6 and 10 years. The sample group consisted of children living in Central Anatolia, without any walking disorder and foot pathology. Approval was obtained from the ethical board committee of Ankara University, and informed consents were obtained from the families of the children included in the sampling before initiation of the study.

Data were collected from 24 different measurements including the shoe size of the dominant foot, metatarsal circumference, TFL, and Staheli arch index. In addition, demographic data such as height, body weight, and body mass index of children were measured (Table 1). The shoe types and sizes used by the children in the sample were subsequently determined.

Table 1

Demographic Data of Children

\begin{tabular}{|lllll|}
\hline & \multicolumn{3}{l}{ Boys } & \multicolumn{3}{l}{ Girls } \\
\cline { 2 - 5 } & Mean Value & Standard Deviation & Mean Value & Standard Deviation \\
\hline Age (years) & 7,4861 & 1,4999 & 7,5903 & 1,3490 \\
\hline Height (meter) & 1,2658 & 0,1056 & 1,2611 & 0,0945 \\
\hline Body weight (kg) & 28,3517 & 7,84902 & 27,9368 & 7,4789 \\
\hline Body Mass Index & 17,3517 & 2,5926 & 17,3041 & 2,7715 \\
\hline Shoe Size & 35,4431 & 3,5080 & 31,9484 & 3,3979 \\
\hline
\end{tabular}

To determine the anthropometric dimensions of the foot, footprints were taken from the foot of the individuals using the foot-print method (Fig. 1.). The knee was flexed while the footprint was taken. The TFL, FL, X, Y, S, Arch Index (B / A + b + C), Chippaux Smirak Index (B / A *100\%), Staheli Arc, and foot rotation values of the children were examined (Table 2 ). In addition, metatarsal circumference and oblique measurements were taken directly from the feet of children (Table 3 ). 
Table 2

Data from Footprint Assessment

\begin{tabular}{|lllll|}
\hline & Boys & \multicolumn{3}{l|}{ Girls } \\
\cline { 2 - 5 } & $\begin{array}{l}\text { Mean } \\
\text { Value }\end{array}$ & $\begin{array}{c}\text { Standard } \\
\text { Deviation }\end{array}$ & $\begin{array}{l}\text { Mean } \\
\text { Value }\end{array}$ & $\begin{array}{l}\text { Standard } \\
\text { Deviation }\end{array}$ \\
\hline Ark Endeks & 11,3700 & 1,13158 & 11,2503 & 0,8554 \\
\hline $\begin{array}{l}\text { Chippaux Smirak } \\
\text { Index }\end{array}$ & 0,6207 & 0,17798 & 0,5647 & 0,1755 \\
\hline Staheli Arc Index & $\% 96,21$ & $\% 27,86$ & $\% 86,80$ & $\% 26,10$ \\
\hline X Value $(\mathrm{cm})$ & 1,5617 & 1,06563 & 1,9658 & 1,0455 \\
\hline Y Value $(\mathrm{cm})$ & 5,7867 & 0,72693 & 5,5374 & 0,8837 \\
\hline S Angle $\left({ }^{\circ}\right)$ & 23,1778 & 14,0184 & 29,6019 & 13,6776 \\
\hline TFL $(\mathrm{cm})$ & 15,5972 & 1,3882 & 15,4161 & 1,3415 \\
\hline FL $(\mathrm{cm})$ & 19,4522 & 1,7917 & 19,2510 & 1,6714 \\
\hline Foot Rotation $\left(^{\circ}\right)$ & 21,9611 & 2,64968 & 21,3806 & 2,2885 \\
\hline
\end{tabular}

Table 3

Data obtained from feet

\begin{tabular}{|lllll|}
\hline & \multicolumn{3}{l}{ Boys } & \multicolumn{3}{l|}{ Girls } \\
\cline { 2 - 5 } & $\begin{array}{l}\text { Mean } \\
\text { Value }\end{array}$ & $\begin{array}{l}\text { Standard } \\
\text { Deviation }\end{array}$ & $\begin{array}{l}\text { Mean } \\
\text { Value }\end{array}$ & $\begin{array}{c}\text { Standard } \\
\text { Deviation }\end{array}$ \\
\hline $\begin{array}{l}\text { Metatarsal Measurement } \\
(\mathrm{cm})\end{array}$ & 18,4606 & 1,69878 & 18,0458 & 1,45648 \\
\hline Oblique $(\mathrm{cm})$ & 25,1044 & 2,6042 & 24,6594 & 2,2820 \\
\hline
\end{tabular}

\section{Statistical Analysis}

Data were analyzed using the Statistical Package for Social Sciences (SPSS), version 23.0. When comparing the parameters, the normality values were first examined. Then, the independent samples ttest was used to analyze sex differences in terms of foot size and shape. To understand the relationship between other parameters, correlations analysis was performed.

Staheli arc index was evaluated by forming seven different groups. The percentages of the participants were determined. Staheli arc index values between $0 \%$ and $19 \%$ were $3^{\circ}$; pes cavus, between $20 \%$ and 
$39 \%$ were $2^{\circ}$; pes cavus, between $40 \%$ and $59 \%$ were $1^{\circ}$; and pes cavus (Fig. 2), between $60 \%$ and $79 \%$ values as normal arc structure (Fig. 3), between $80 \%$ and $79 \%$ values as $1^{\circ}$, between $100 \%$ and $119 \%$ values as $2^{\circ}$, and $120 \%$ and above values as $3^{\circ}$. It was classified as pes planus and evaluated (Fig. 4).

\section{Results}

The participants of the study consisted of 335 children ( 155 girls and 180 boys) aged between 6 and 10 (average: 8) years living in Central Anatolia. The body weights of the participants were between 14,60 $55,50 \mathrm{~kg}$ and their heights were between $96-152 \mathrm{~cm}$.

When the TFL values of the children were examined, the range was $11.50-19.80 \mathrm{~cm}$, and the median was $15.5 \mathrm{~cm}$. The normal distribution of the TFL values was found to be good. The range of the foot length was $14.12-24.89 \mathrm{~cm}$, and the median was $19.28 \mathrm{~cm}$. When the FL values were examined, the range was $14.00-25.50 \mathrm{~cm}$, and the median was $19.2 \mathrm{~cm}$; the values were found to be normally distributed. The range of the first metatarsal to ground distance was $0.83-3.80 \mathrm{~cm}$, and the median value was $1.65 \mathrm{~cm}$. When Chippaux Smirak index values were examined, the range was $0.00-1.01$, and the median was 0.57 .

Further, the correlation ( 0.177$)$ between body mass index and foot rotation was found to be very weak.

When the correlation results of $S$ value were analyzed, a weak correlation was observed between the $S$, Navicular ground distance, and 1st Metatarsal ground distance. Additionally, a weak correlation (-0.369) was found between the Chippaux Smirak index and Navicula to ground distance.

When the correlation analysis with other values of the Staheli Arc Index was examined, a weak correlation between the LLA angle and Navicula ground distance was observed. There were also weak correlations between the LLA angle, body mass index, foot rotation, and calcaneus angle.

A strong correlation (0.795) was observed between the TFL and Metatarsal circumference, as well as between the TFL and oblique measurement (coefficient, 0.848). Further, strong correlations were found between age and the TFL (coefficient, 0.727), FL (coefficient, 0.748), oblique measurement (coefficient, 0.721), arc index (coefficient, 0.717), shoe size (coefficient, 0.723), and foot length (coefficient, 0.650); however, the correlations between age and the 1st metatarsal to ground distance (coefficient, 0.294), Chippaux Smirak Index (coefficient, -0.133), Staheli Arc Index (coefficient, -0.129), and foot rotation (coefficient, -0.030) were weak.

A relationship was found between the metatarsal circumference and sex, which was stronger in the boys than in the girls $(P=0.18)$. No significant differences were observed between the sexes in terms of the $1 \mathrm{st}$ metatarsal to ground distance, TFL ( $P=0.227)$, and foot length; however, there was a statistically significant difference in foot rotation between the sexes $(P=0.034)$, with girls having smaller foot rotation than boys. 
According to the evaluation results with the classification made with the Staheli arch index, $0.30 \%$ of the sample was $3^{\circ}$ pes cavus ( 1 individual [ 1 male]), $2.69 \% 2^{\circ}$ pes cavus ( 9 individuals [ 1 male, 8 female]), $6.87 \% 1^{\circ}$ pes cavus ( 23 individuals [9 boys, 14 girls]), $27.76 \%$ of the normal arch structure (93 individuals [48 boys, 45 girls]), $22.09 \% 1^{\circ}$ pes planus ( 74 individuals [ 39 boys, 35 girls]), $17.70 \% 2^{\circ}$ pes planus (66 individuals [ 37 boys, 29 girls]), and $20.60 \% 3^{\circ}$ pes planus ( 69 individuals [ 45 boys, 24 girls]) were identified (Table 4).

Table 4

Distribution of children according to low arc values

\begin{tabular}{|lllll|}
\hline Values & Diagnosis & Number of Children & Boy & Girl \\
\hline $0 \%-19 \%$ & High Arc (Pes Cavus) & 1 & 1 & 0 \\
& $3 .^{\circ}$ & & & \\
\hline $20 \%-39 \%$ & High Arc (Pes Cavus) & 9 & 1 & 8 \\
& $2 .^{\circ}$ & & & \\
\hline $40 \%-59 \%$ & High Arc (Pes Cavus) & 23 & 9 & 14 \\
& $1 .^{\circ}$ & & & \\
\hline $60 \%-79 \%$ & Normal Arc & 93 & 48 & 45 \\
\hline $80 \%-99 \%$ & Low Arc (Pes Planus) & 74 & 39 & 35 \\
& $1 .^{\circ}$ & & & \\
\hline $100 \%-119 \%$ & Low Arc (Pes Planus) & 66 & 37 & 29 \\
& $2 .^{\circ}$ & & & \\
\hline $120 \%$ and Over & Low Arc (Pes Planus) & 69 & 45 & 24 \\
& 3. & & & 180 \\
\hline
\end{tabular}

According to the data determined in the classification made via the Staheli arch index, pes cavus is more common in girls than in boys. However, pes planus is more common in boys than in girls. Based on the Staheli arc index, almost the same number of girls and boys had a normal arc structure.

\section{Discussion}

This study evaluated the foot measurements of children living in Central Anatolia using different methods. The rate of increase in foot sizes of girls and boys aged between 6 and 10 years varied. When 

TFL was smaller in boys than in girls.

\section{The relationship between foot length and other parameters of children}

Foot length was strongly correlated with age ( $r=0.736$ for girls; $r=0.725$ for boys). Foot length and height were strong correlated ( $r=0.906$ for girls; $r=0.887$ for boys). Body weight and foot length of children were strongly correlated ( $r=0.822$ for girls; $r=0.836$ for boys). There was a strong correlation between the metatarsal circumference measurements and foot length ( $r=0.756$ for girls; $r=0.817$ for boys). The relationships between the oblique measure and foot height of children $(r=0.837$ for girls; $r=0.858$ for boys) and between the calculated arch index and foot length ( $r=0.946$ for girls; $r=0.946$ for boys) were strong. It was determined that the foot height had a moderate relationship with the $X$ angle $(r=0.695$ for girls; $r=0.625$ for boys). The distance of the medial malleolus to the ground was moderately related to the height of the foot ( $r=0.526$ for girls; $r=0.546$ for boys).

\section{Comparison of FL with other nations}

In this study, FL values of Turkish children at different ages were examined. In this context, these were evaluated in different countries. Xu's study also used data from Chinese children [5]. Delgado's study included data of Spanish children [6]. Barisch's [7] study included data of German children and Waseda's [8] study included data from Japanese children. Data of Mexican children were included in Prado-Leon's study [9]. In these studies, the age ranged from 6 to 12 years. In addition to the comparison, Bari's study included boys aged 5 and 6 years [10]. The data are given in Fig. 5 .

The height of the navicular can be defined as the distance from the base of the medial projection of the navicular tuberosity to the ground. When the relationship between navicular height and age was examined, a low correlation was observed ( $r=0.344$ for girls; $r=0.354$ for boys). Figure 6 shows the comparison of Turkish children with navicular height and Waseda's (2014) study with Japanese children [8].

The arc index value of Turkish children was also calculated and compared with that of children from other countries. In this context, the arch index values of German children were taken from Müller's study [11]. The arch index values of children living in two different countries are given in Fig. 7.

The Chippaux Smirak index of Turkish children was examined by age [12]. Comparison of children with those from other nations has been made. Sacco's [13] study obtained the values of Brazilian and German children. A comparison of Echarri's [1] study with children in Congolese with Turkish children was made. The Chippaux Smirak indexes of children from four different countries are given in Fig. 8.

The Staheli Arc values of children were examined according to age [14]. However, the Staheli Arc values of Turkish children were compared with those of Brazilian, German, and Congolese children. Comparison 
of Staheli Arc values is given in Fig. 9.

\section{Conclusion}

This study aimed to determine the foot sizes and foot structures of children living in Central Anatolia. The results of the study may be used as an important resource for shoe designers in terms of child foot health. Foot structures of children aged $6-10$ years were shown to be different according to sex and increasing age. The data of the study varies according to the number of individuals participating in the sampling and the techniques used to measure the foot structure; therefore, increasing the sample size and the use of three-dimensional scanning system to analyze Turkey's different regions of the foot and arch structure is proposed.

\section{Declarations}

\section{Acknowledgements}

We would like to give our great appreciation to the school children and their parents who participated in this study.

\section{Authors' contributions}

S.A., S.G., E.G., A.O., Y.A.: developed study protocol, study material, collected the data, preliminary analysis of data and did the final write up. S.A., N.A.: supervisor, conceptualisation of study, assisted with data collection and reviewing data analysis and review of final write up; All authors have read and approved the manuscript.

\section{Funding}

This work did not receive any funding.

\section{Availability of data and materials}

All the data that support the findings of this study are contained within the manuscript. Any requests for additional data can be made available upon reasonable request from the corresponding author and with permission of Ethics Department of the University of Ankara.

\section{Conflict of Interest}

The author(s) declared no potential conflicts of interest with respect to the research, authorship, and/or publication of this article.

\section{Ethics approval and consent to participate}


The study was conducted in accordance with the Declaration of Helsinki. Consent to participate was obtained from the parents/ guardians of the minors included in this study (minors are considered anyone under the age of 16). The protocol was approved by the Medical Science Ethics Committee of Ankara University (No.16/242). Parents and children provided their written consent to participate.

\section{Consent for publication}

Not applicable.

\section{Competing interests}

The authors declare that they have no competing interests.

\section{References}

1. Echarri JJ, \& Forriol F. The development in footprint morphology in 1851 Congolese children from urban and rural areas, and the relationship between this and wearing shoes. Journal of Pediatric Orthopaedics B. 2003;12(2):141-146.

2. Hawes MR, Sovak D, Miyashita M, et al.Ethnic differences in forefoot shape and the determination of shoe comfort. Ergonomics. 1994;37:187-96.

3. Kouchi M. Foot dimensions and foot shape: Differences due to growth, generation and ethnic origin. Anthropological Science. 1998:106:161-88

4. Tomassoni D, Traini E, Amenta F. Gender- and age-related differences in foot morphology. Maturitas. 2014;79:421-27.

5. Xu M, Hong Y, Li JX, \& Wang L. Foot morphology in Chinese school children varies by sex and age. Medical science monitor: international medical journal of experimental and clinical research. 2018;24: 4536.

6. Delgado-Abellan L, Aguado X, Jimenez-Ormeno E, et al. Foot morphology in Spanish school children according to sex and age. Ergonomics 2014;57:787-97

7. Barisch-Fritz B, Plank C, \& Grau S. Evaluation of the rule-of-thumb: calculation of the toe allowance for developing feet. Footwear Science. 2016;8(3): 119-127.

8. Waseda A, Suda Y, Inokuchi S, et al. Standard growth of the foot arch in childhood and adolescence - derived from the measurement results of 10,155 children. Foot Ankle Surg. 2014;20:208-14.

9. Prado-León LR, Avila-Chaurand R \& Gonzalez-Munoz EL. Anthropometric study of Mexican primary school children. Applied Ergonomics 2001;32(4):339-345.

10. Bari SB, Othman, $M, \&$ Salleh, NM. Foot anthropometry for shoe design among preschool children in Malaysia. Pertanika J Soc Sci Humanit 2010;18: 69-79.

11. Müller S, Carlsohn A., Müller J, Baur H \& Mayer F. Static and dynamic foot characteristics in children aged 1-13 years: a cross-sectional study. Gait \& Posture 2012:35(3); 389-394. 
12. Forriol F, Pascual J. Footprint analysis between three and seventeen years of age. Foot Ankle 1990:11(2);101-4.

13. Sacco IC, Onodera AN, Bosch K \& Rosenbaum D.Comparisons of foot anthropometry and plantar arch indices between German and Brazilian children. BMC Pediatrics 2015;15(1): 4.

14. Staheli LT, Chew DE, Corbett M. The longitudinal arch. A survey of eight hundred and eighty-two feet in normal children and adults. J Bone Joint Surg Am.1987;69(3):426-8.

\section{Figures}

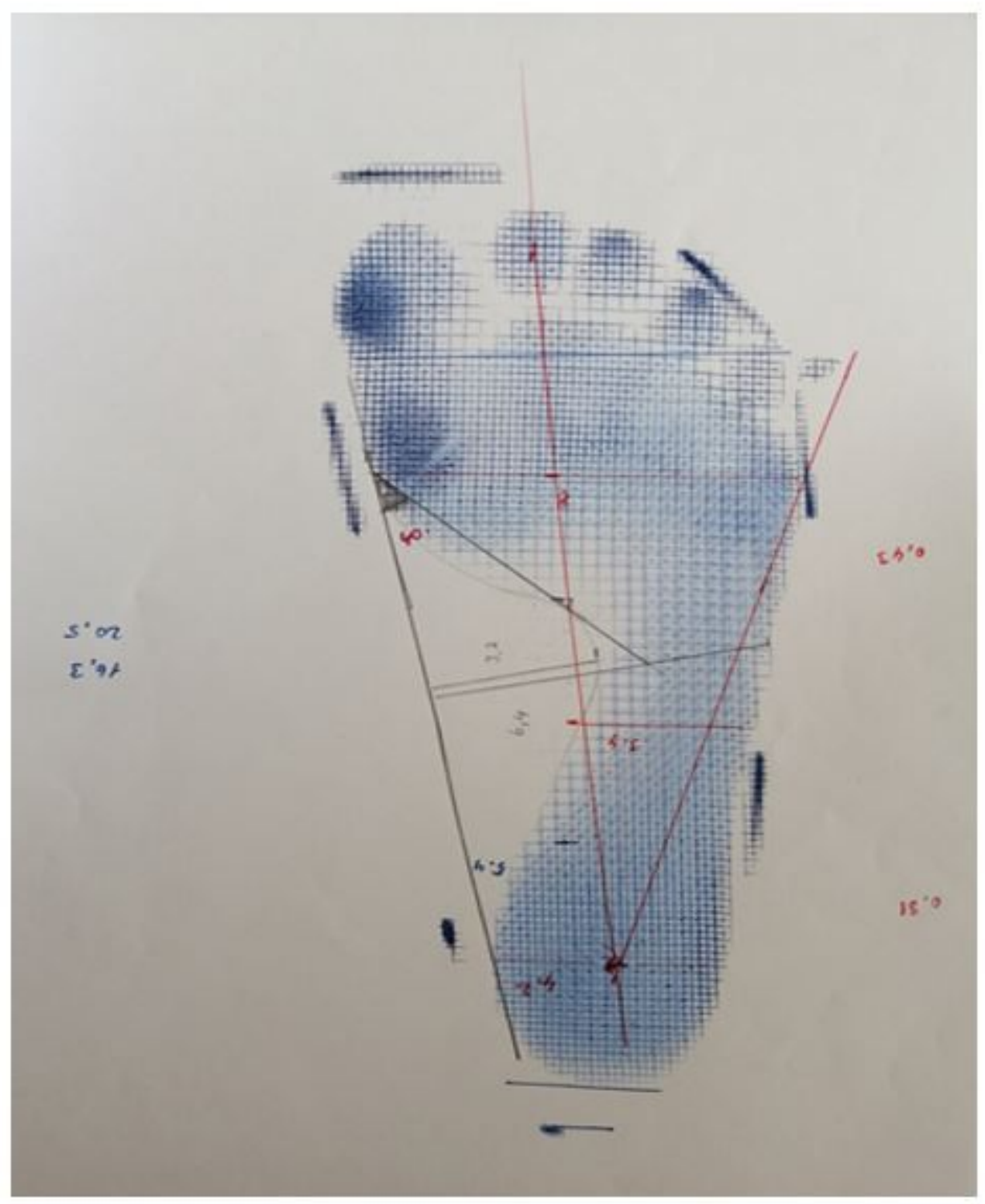

Figure 1

Footprint taken by Foot-Print method 

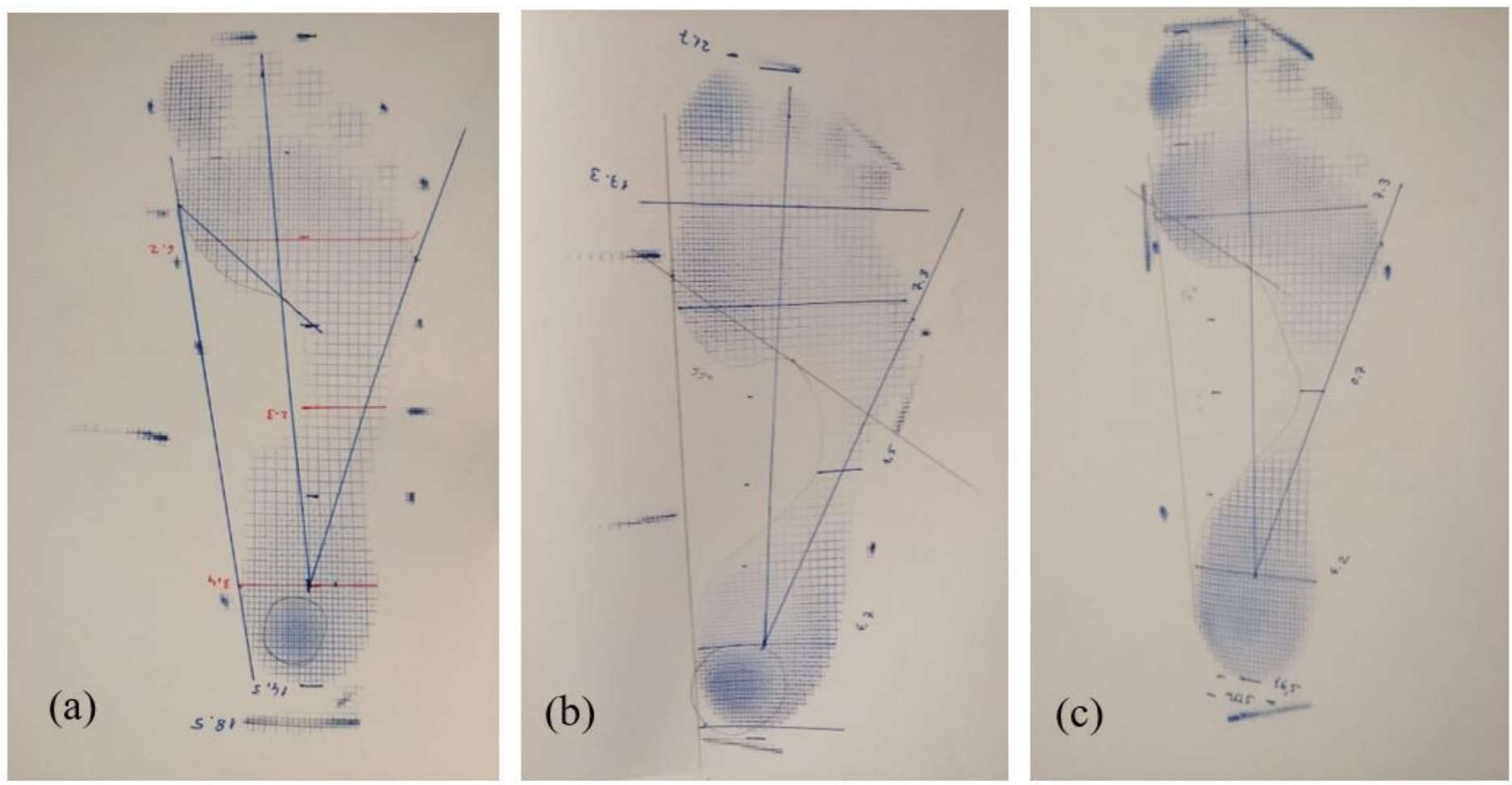

\section{Figure 2}

Arc height; (a) 1. o Pes Kavus, (b) 2. o Pes Kavus, (c) 3. o Pes Kavus 


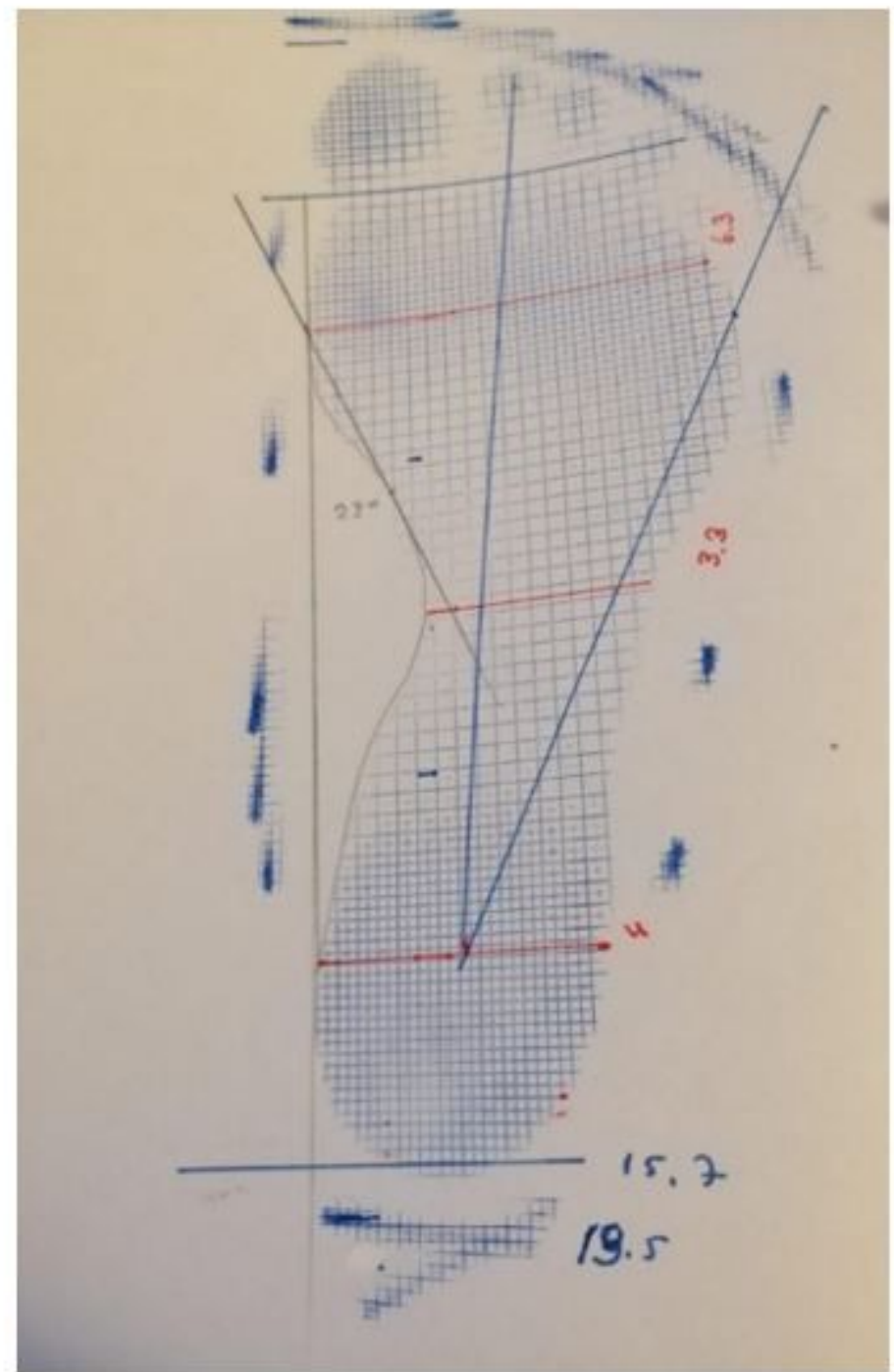

Figure 3

Normal arc structure

Page 12/18 

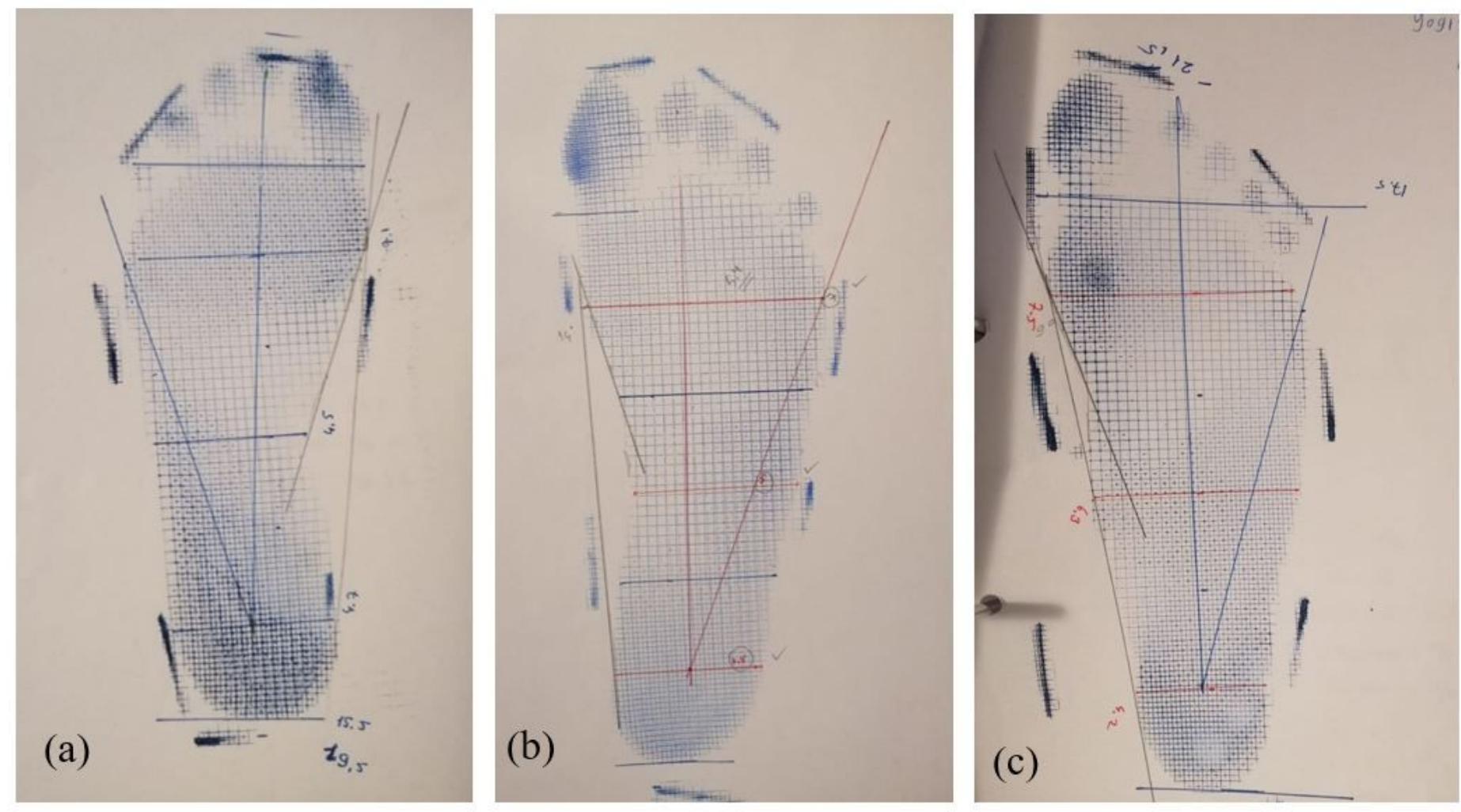

\section{Figure 4}

Arc drop; (a) 1. o Pes Planus, (b) 2. o Pes Planus, (c) 3. o Pes Planus 


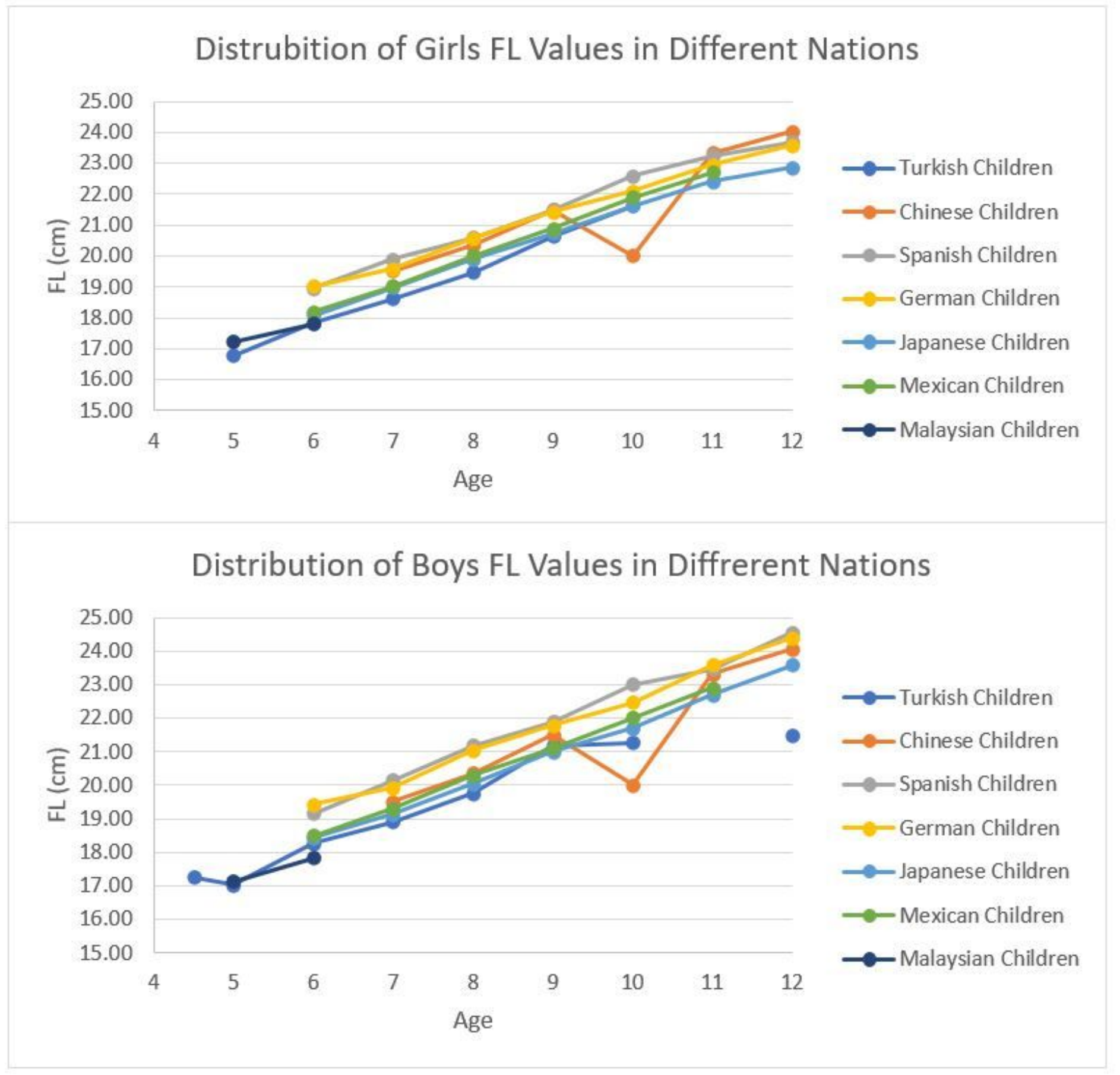

\section{Figure 5}

In these studies, the age ranged from 6 to 12 years. In addition to the comparison, Bari's study included boys aged 5 and 6 years [10]. The data are given in Figure 5. 

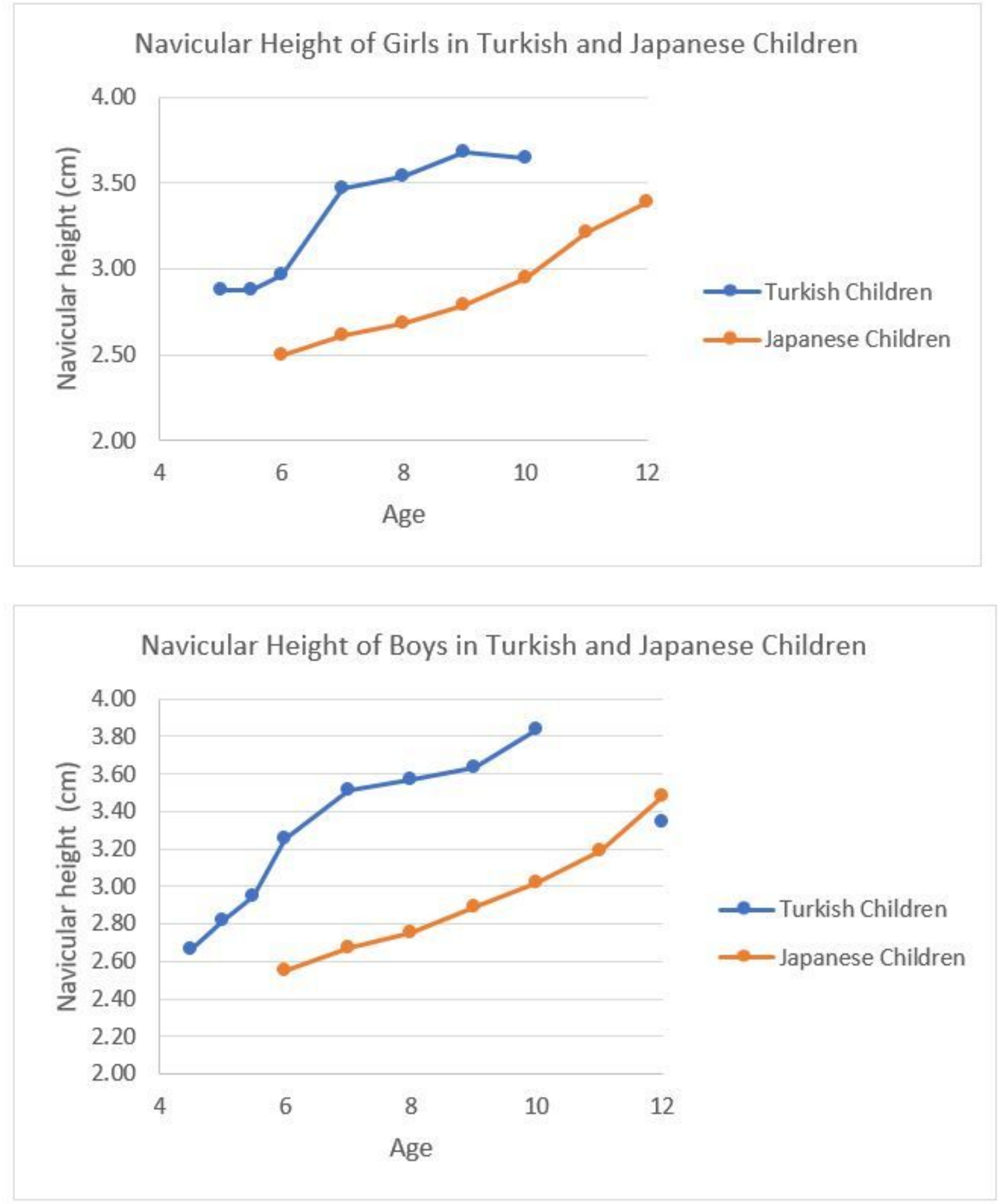

\section{Figure 6}

Figure 6 shows the comparison of Turkish children with navicular height and Waseda's (2014) study with Japanese children [8]. 


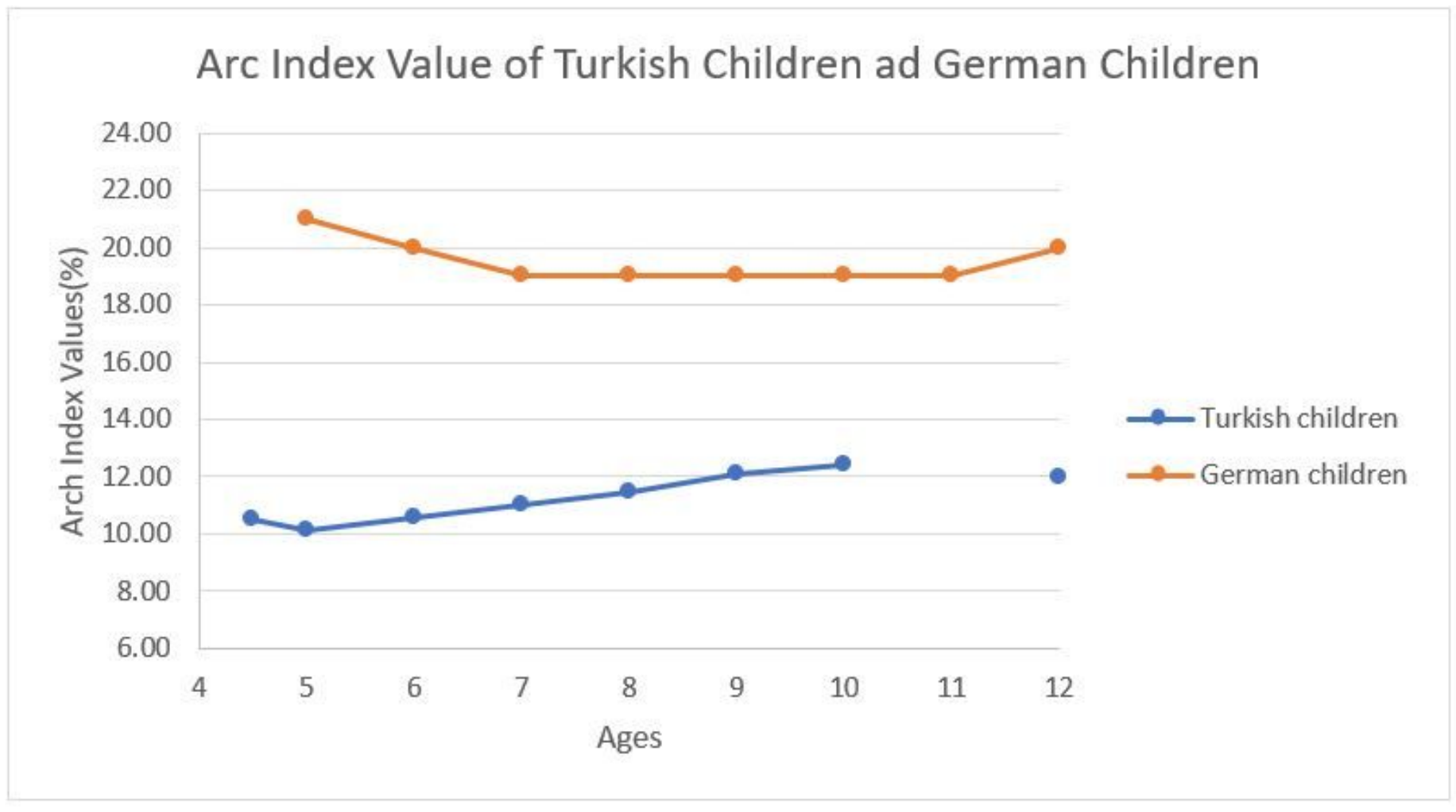

Figure 7

In this context, the arch index values of German children were taken from Müller's study [11]. The arch index values of children living in two different countries are given in Figure 7. 


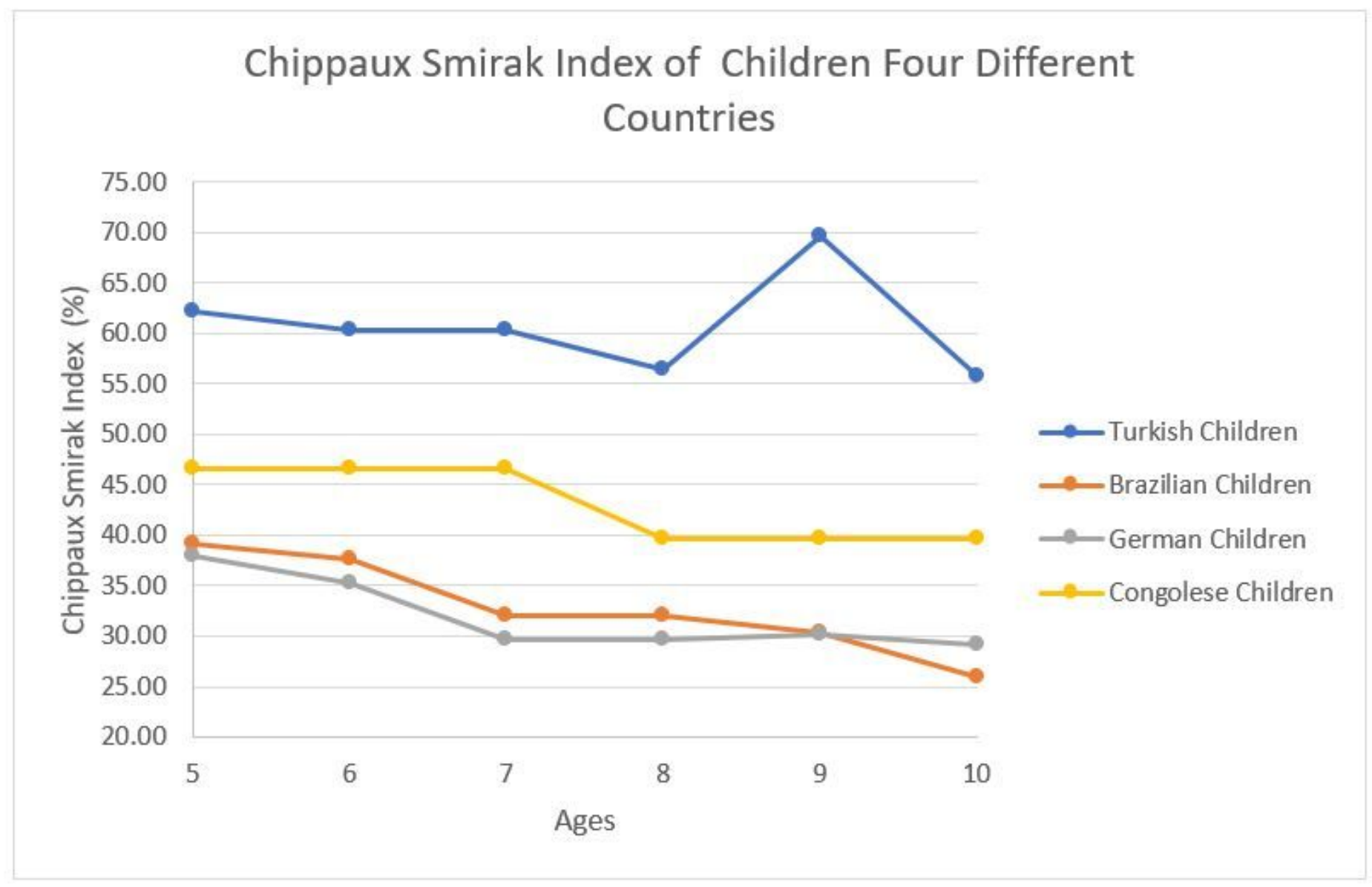

\section{Figure 8}

A comparison of Echarri's [1] study with children in Congolese with Turkish children was made. The Chippaux Smirak indexes of children from four different countries are given in Figure 8. 


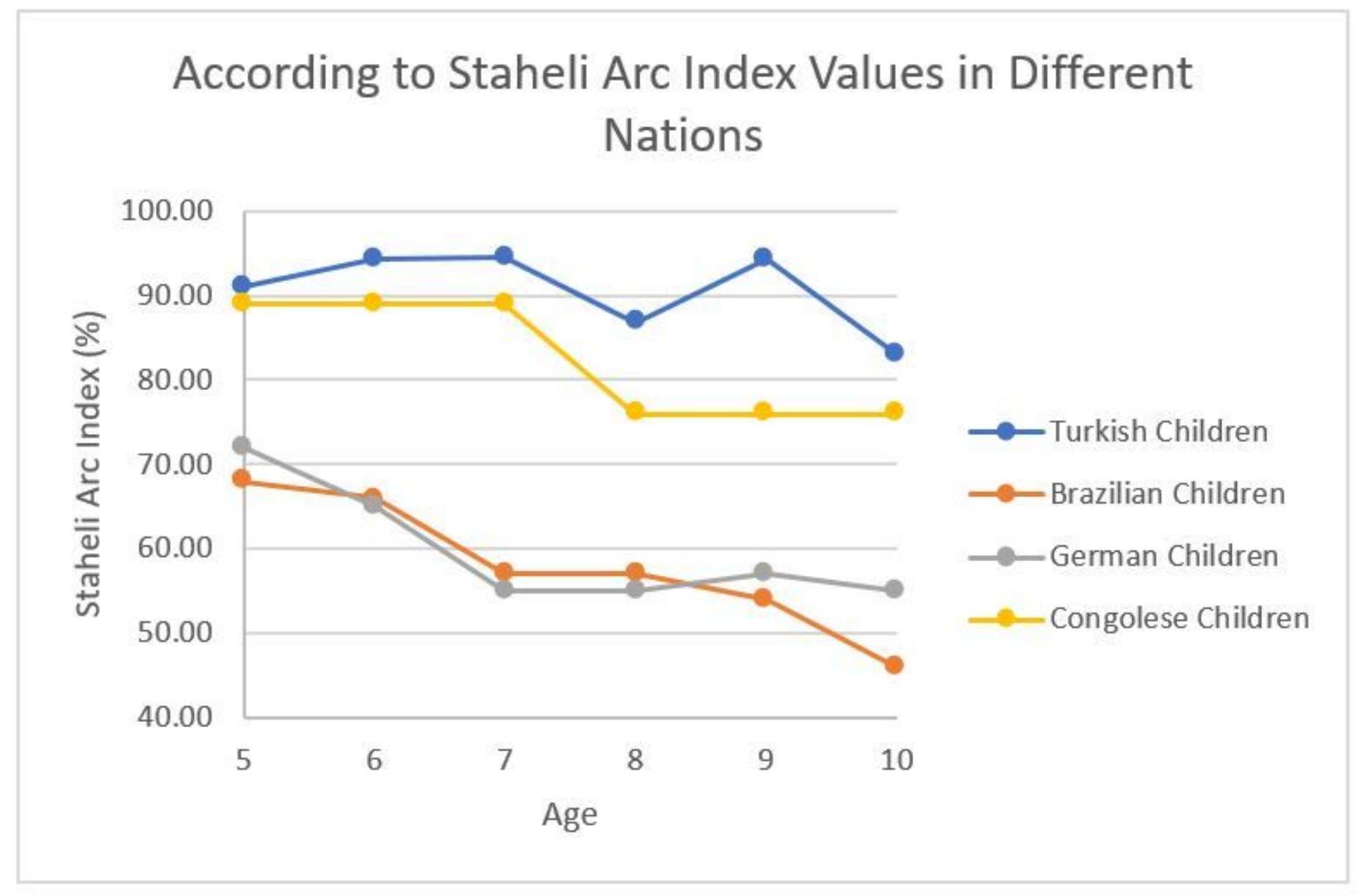

\section{Figure 9}

The Staheli Arc values of children were examined according to age [14]. However, the Staheli Arc values of Turkish children were compared with those of Brazilian, German, and Congolese children. Comparison of Staheli Arc values is given in Figure 9. 